\title{
1 \\ Ocorrência de Listeria spp. em salame tipo Italiano comercializados em supermercados do bairro de Casa Amarela, Recife-PE
}

\author{
[Occurrence of Listeria spp. in Italian type salami sold in supermarkets in the neighborhood of Casa \\ Amarela, Recife-PE]
}

\section{"Comunicação Breve/Short Communication"}

\author{
Camila Araújo Sousa de Sá Pessoa, Breno Bezerra Aragão*, Caio Alves da Costa, Haliny Cristina \\ Silva Santos, Maria Goretti Varejão da Silva, Andrea Paiva Botelho Lapenda de Moura
}

Departamento de Medicina Veterinária, Universidade Federal Rural de Pernambuco (UFRPE), Recife-PE, Brasil.

*Autor para correspondência/Corresponding author: E-mail: breno.aragao100@ hotmail.com

\begin{abstract}
Resumo
Atualmente, os alimentos prontos para consumo têm se popularizado. Isto se deve ao fato da conveniência e propriedades nutricionais encontradas nesses produtos. Embora sofram processamento tecnológico na fabricação, falhas higiênico-sanitárias podem se tornar um sério risco à saúde do consumidor devido à veiculação de patógenos. Dentre estes, destaca-se o gênero Listeria que tem importância para a indústria de alimentos e saúde pública. Assim, objetivou-se neste estudo a detecção de Listeria spp. em salames tipo Italiano fatiados, embalados a vácuo e comercializados em supermercados do bairro de Casa Amarela, Recife-PE. Foram coletadas 22 amostras de salames tipo Italiano fatiados, embalados a vácuo das três principais marcas brasileiras, estas foram analisadas de acordo com a metodologia da Instrução Normativa de n62/2003 do Ministério da Agricultura Pecuária e Abastecimento. Dentre as amostras estudadas foi detectada uma ocorrência de $13,64 \%$ (3/22), este dado revela possíveis falhas na elaboração do alimento estudado, além de evidenciar a presença de Listeria spp. em salames tipo Italiano fatiados e embalados a vácuo.
\end{abstract}

Palavras-chave: segurança dos alimentos; inspeção; produtos cárneos; doença transmitida por alimento.

\begin{abstract}
Nowadays, ready-to-eat foods have become popular. This is due to the convenience and nutritional properties found in these products. Although undergoing technological processing during production, hygienic-sanitary failures can become a serious risk to consumer health due to the transmission of pathogens. Among these, the genus Listeria stands out, which is important for the food industry and public health. Thus, the objective of this study was to detect Listeria spp. in Italian type salami sliced, vacuum-packed and sold in supermarkets in the neighborhood of Casa Amarela, Recife-PE. Twenty-two samples of Italian type salami, sliced and vacuum-packed, were collected from three main Brazilian brands, these were analyzed according to the methodology from the Normative Instruction n. 62/2003 of the Ministry of Agriculture, Livestock and Supply. Among the studied samples, an occurrence of $13.64 \%$ (3/22) was detected, this data reveals possible flaws in the preparation of the studied food, in addition to showing the presence of Listeria spp. in sliced and vacuum-packed Italian type salami.
\end{abstract}

Keywords: food safety; inspection; meat products; foodborne illness.

Atualmente, a demanda por alimentos de alta qualidade é extremamente considerada pelos consumidores no mundo, sendo os alimentos prontos para o consumo (denominado do inglês ready-to-eat) avaliados os mais importantes devido às características atribuídas à sua conveniência e propriedades saudáveis, permitindo-lhes amplo espaço no cotidiano das pessoas (Possas et al., 2017). 
Devido a este cenário e aliado ao fato de que certos tipos de alimentos não sofrem nenhum tratamento térmico antes do consumo, torna-se necessário que a cadeia produtora e distribuidora de produtos alimentícios garanta o atendimento dos parâmetros microbiológicos, minimizando o risco da disseminação de doenças transmitidas, bem como formas de controle para redução de contaminações por microrganismos no estágio de processamento e elaboração de alimentos (Mahgoub et al., 2019).

Dentre as mais importantes infecções de origem alimentar para saúde pública, destaca-se a listeriose, doença considerada zoonótica e que na maioria dos casos pode apresentar-se como uma doença febril, mas em sua forma mais grave pode causar quadros de aborto e problemas neurológicos (Guillet et al., 2010). A incidência de listeriose é muito maior em populações suscetíveis, incluindo gestantes, idosos e indivíduos com sistema imunológico comprometido (Robert et al., 2017).

A listeriose é uma enfermidade causada por bactérias do gênero Listeria, e este abrange oito espécies: Listeria monocytogenes, L. ivanovii, $L$. innocua, L. welshimeri, L. grayi, L. seeligeri, $L$. rocourtiae e L. marthii. As espécies L. rocourtiae, isolada de alfaces na Áustria em 2002, e $L$. marthii, isolada de um lago da Finger Lakes National Forest em Nova York, Estados Unidos, foram descritas por Leclercq et al. (2010) e Graves et al. (2010), respectivamente. Dentre as espécies destaca-se a L. monocytogenes, por ser reconhecida como agente zoonótico de maior relevância para saúde pública (Oliveira et al., 2010).

No Brasil foram realizados poucos estudos sobre a veiculação de Listeria spp. em salames embalados a vácuo e em outros alimentos prontos para consumo (Borges et al., 1999; Araújo et al., 2002; Sakate et al., 2003).

Devido à importância do gênero Listeria para a indústria de alimentos e saúde pública, objetivou-se neste estudo a detecção de Listeria spp. em salames tipo Italiano fatiados embalados a vácuo comercializados em supermercados do bairro de Casa Amarela, Recife-PE.

A amostragem utilizada neste estudo foi tipo não probabilística por conveniência (Sampaio, 1998). Foram coletadas 22 amostras de salames tipo Italiano fatiado embalado a vácuo das três principais marcas brasileiras comerciais adquiridas em supermercados do bairro de Casa
Amarela no município de Recife-PE (Figura 1). O número de amostras adquiridas por estabelecimento foi definido a partir da observação realizada in loco de acordo com os estabelecimentos que comercializavam salames tipo Italiano fatiados embalados a vácuo.

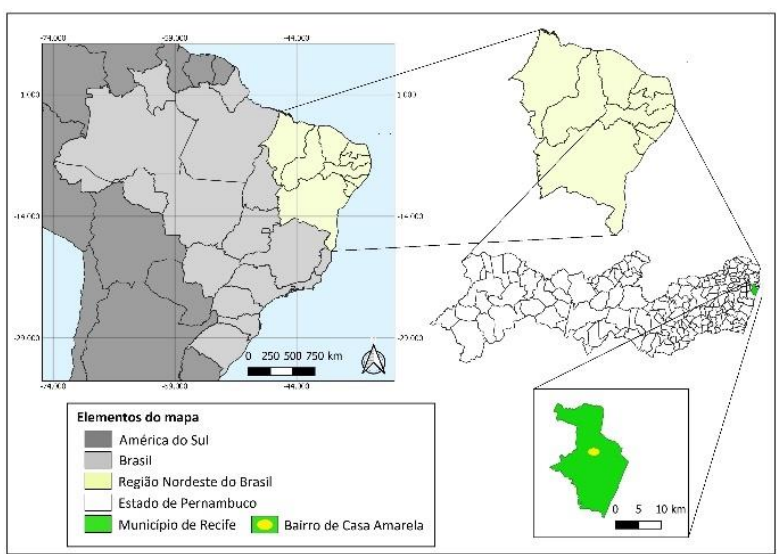

Figura 1. Localização geográfica do bairro dos estabelecimentos amostrados no município de Recife.

Cada amostra pesava $100 \mathrm{~g}$ e todas estavam dentro do período de validade estipulado pelo fabricante, após a obtenção foram armazenadas em sacos esterilizados tipo zip (Talge Brasil LTDA., Tailândia) e devidamente identificados, sendo acondicionadas em caixas isotérmicas com gelo reciclável e transportadas para a realização das análises microbiológicas no Laboratório de Inspeção de Carne e Saúde Pública (LICASP) do Departamento de Medicina Veterinária, Sede/UFRPE.

Para a pesquisa de Listeria spp. foram utilizados os métodos analíticos oficiais para análises microbiológicas para controle de Produtos de Origem Animal, preconizados pelo Ministério da Agricultura Pecuária e Abastecimento (MAPA), na Instrução Normativa $\mathrm{n}^{\circ}$ 62, de 26 de agosto de 2003 (BRASIL, 2003). Foram pesados $25 \pm 0,2 \mathrm{~g}$ gramas de diversas partes de cada amostra, que foram transferidas diretamente para um frasco estéril contendo 225 $\mathrm{mL}$ de caldo UVM (Difco Laboratories Inc., Detroit, Estados Unidos) adicionado de seu suplemento, sendo incubado a $30 \pm 1^{\circ} \mathrm{C}$ por 24 a 48 horas. Após o período de incubação, foi aliquotado $0,1 \mathrm{~mL}$ da cultura para tubo de ensaio contendo $10 \mathrm{~mL}$ de caldo Fraser (Merck, Estados Unidos) e incubado a $30^{\circ} \pm 1^{\circ} \mathrm{C}$ por 24 a 48 horas.

Posterior ao enriquecimento do caldo Fraser, com auxílio de uma alça de platina de cinco (5) $\mathrm{mm}$ de diâmetro, foi retirada uma 
alíquota e inoculada por meio da técnica de esgotamento de superfície em estrias em placas contendo Ágar Palcam (AP) (Difco Laboratories Inc., Detroit, Estados Unidos) de forma a proporcionar a obtenção de colônias isoladas. As placas de AP foram incubadas na temperatura de $30^{\circ} \mathrm{C}$ por 24 a 48 horas.

Após o período foram selecionadas três colônias típicas sugestivas de Listeria monocytogenes de cada placa de meio de cultivo de acordo com os critérios da Instrução Normativa n'62/2003 (BRASIL, 2003). Todas as colônias selecionadas foram submetidas à técnica de coloração de Gram (Stinghen et al., 2002). Após a confirmação morfotintorial (bacilos pequenos Gram positivos), os isolados bacterianos foram submetidos às provas bioquímicas de produção de catalase, motilidade característica, reação de vermelho de metila (VM) e reação de CAMP em ágar sangue de ovino a 5\%, todas estas determinadas pela Instrução Normativa nº $62 / 2003$ (BRASIL, 2003).

A análise estatística dos resultados foi realizada de forma descritiva das variáveis relativas à presença ou ausência da Listeria spp. nas amostras de salame através do cálculo de frequência absoluta e relativa (Bussab e Morettin, 2006).

Das 22 amostras de salames tipo Italiano fatiados embalados a vácuo, foram selecionadas um total de 66 colônias típicas sugestivas de Listeria monocytogenes (três colônias por amostra), destas, apenas três isolados foram positivos em todas as provas bioquímicas, que as caracterizaram do gênero Listeria. Em relação à contaminação das amostras por Listeria spp., três amostras estavam contaminadas, representando uma ocorrência de 13,64\% (3/22).

Atualmente no Brasil, apenas Listeria monocytogenes é referenciada na legislação vigente quanto a sua presença ou ausência em alimentos (BRASIL, 2001; BRASIL, 2009), as demais espécies são negligenciadas. Entretanto, a detecção de Listeria spp. em alimentos revela uma possível contaminação por falhas higiênicosanitárias na fabricação, uma vez que esses microrganismos são amplamente disseminados no meio ambiente, tais como: água, solo, vegetais, plantas em decomposição, esgotos, fezes de animais saudáveis e também de humanos (Liu, 2006). Além disso, esses microrganismos podem tolerar variações extremas de $\mathrm{pH}$, temperatura, concentrações de sal e aderir-se rapidamente à superfície de equipamentos em aço inoxidável e utensílios utilizados para fabricação de alimentos, sendo capaz de se multiplicar, formando biofilmes, favorecendo a contaminação do produto final (Maury et al., 2019).

Considerando-se os resultados das amostras positivas analisadas, pode-se sugerir que as instalações industriais e/ou matérias-primas utilizadas para elaboração dos salames tipo Italiano fatiados embalados a vácuo não atendiam os requisitos mínimos exigidos pela Instrução Normativa $\mathrm{N}^{\circ} \quad 9 / 2009$ do Ministério da Agricultura, Pecuária e Abastecimento (BRASIL, 2009), que tem por objetivo monitorar e assegurar a inocuidade de produtos prontos para consumo, principalmente em relação à espécie Listeria monocytogenes, comprovando a importância do monitoramento das indústrias de produtos de origem animal que elaboram produtos prontos para consumo.

Apesar das condições de conservação terem sido respeitadas pelos estabelecimentos comerciais, as contaminações de ambientes industriais podem favorecer a contaminação de alimentos por Listeria spp. Algumas cepas de Listeria sp. tem a capacidade de crescer em biopelículas na superfície de diversos alimentos, e a refrigeração aumenta, na realidade, o crescimento desse microrganismo, em virtude de sua capacidade de crescer a $4^{\circ} \mathrm{C}$ (Jay, 2005). Deve-se salientar que o agente pode se multiplicar em salames embalados a vácuo quando contaminados por Listeria sp. e passa a oferecer risco aos consumidores, principalmente em indivíduos imunodeprimidos e que não dispõem de informações acerca da possibilidade de sua presença neste tipo de alimento, principalmente quando se trata da espécie L. monocytogenes (Sakate et al., 2003).

O controle Listeria spp. no ambiente de manipulação de alimentos é dificultado pelo fato da bactéria ter sua origem principalmente ambiental. Desta forma, há necessidade da análise frequente para a deteç̧ão em produtos e amostras ambientais objetivando o controle efetivo deste patógeno nos estabelecimentos e manipuladores de alimentos (Barancelli et al., 2011).

Nesse panorama, é indispensável ressaltar a importância da realização de inspeção sanitária nas diversas etapas de elaboração de alimentos, estas abrangem os locais de fabricação, armazenamentos, distribuição e comercialização. Além da aplicação das Boas Práticas de 
Fabricação, Procedimentos Padrão de Higiene Operacional e Análise de Perigo e Pontos Críticos de Controle, visando, assim, um alimento seguro aos consumidores.

O gênero Listeria apresenta-se como um dos patógenos mais relevantes para saúde pública, devido a sua capacidade de causar quadros de infecções alimentares. Os resultados obtidos neste estudo evidenciam a ocorrência de Listeria spp. em salames tipo Italiano fatiados embalados a vácuo comercializados em supermercados no município de Recife-PE, revelando a necessidade de medidas de controle higiênico-sanitário para a redução de fatores que contribuem com a contaminação de salames por esses microrganismos nos estabelecimentos industriais durante o processo de elaboração, bem como, intensificar ações de inspeção e controle de qualidade. Os dados podem ainda nortear ações fiscalizatórias dos órgãos competentes governamentais na industrialização de embutidos, fornecendo assim um alimento seguro aos consumidores.

\section{Conflito de Interesse}

Os autores declaram não existir conflitos de interesse.

\section{Referências}

Araújo, P.C.C.; Franco, R.M.; Oliveira, L.A.T.; Carvalho, J.C.A.P. Ocorrência de Listeria monocytogenes em produtos de carne de peru comercializados na cidade de Niterói-RJBrasil. Acta Scientiae Veterinariae, 30(1): 19-25, 2002.

Barancelli, G.V.; Silva-Cruz, J.V.; Porto, E.; Oliveira, C.A.F. Listeria monocytogenes: Ocorrência em produtos lácteos e suas aplicações em saúde pública. Arquivos do Instituto Biológico, 78(1): 155-168, 2011.

Borges, M.F.; Siqueira, R.S.; Bittencourt, A.M.; Vanetti, M.C.D.; Gomide, L.A.M. Ocorrência de Listeria monocytogenes em salame. Revista de Microbiologia, 30(4): 362-364, 1999.

BRASIL. Ministério da Saúde. Resolução-RDC $\mathrm{n}^{\mathbf{0} 12}$, de 02 de janeiro de 2001. Aprova Regulamento técnico sobre os padrões microbiológicos para alimentos. Diário Oficial [da] República Federativa do Brasil, Brasília, 2001. Disponível em:< http://portal.anvisa.gov.br/documents/33880/2 568070/RDC_12_2001.pdf/15ffddf63767- 4527-bfac-740a0400829b> Acesso em: 20 abr. 2020.

BRASIL. Ministério da Agricultura, Pecuária e Abastecimento. Instrução Normativa $n^{0} 62$ de 26 de agosto de 2003. Oficializa os Métodos analíticos oficiais para análises microbiológicas para controle de produtos de origem animal e água. Brasília: Ministério da Agricultura, Pecuária e Abastecimento, 2003. Disponível em: <http://www.agricultura.gov.br/>. Acesso em: 15 ago. 2019.

BRASIL. Ministério da Agricultura, Pecuária e Abastecimento. Instrução Normativa $\mathbf{n}^{\mathbf{0}} 9$ de 8 de abril de 2009. Oficializa os Procedimentos de Controle da Listeria monocytogenes em produtos de origem animal prontos para o consumo. Brasília: Ministério da Agricultura, Pecuária e Abastecimento, 2009. Disponível em: <http://www.agricultura.gov.br/>. Acesso em: 17 ago. 2019.

Bussab, W.O.; Morettin, P.A. Estatistica básica. $5^{a}$ ed. São Paulo: Saraiva, 2006.

Graves, L.M.; Helsel, L.O.; Steigerwalt, A.G.; Morey, R.E.; Daneshvar, M.I.; Roof, S.E.; Orsi, R.H.; Fortes, E.D.; Milillo, S.R.; Den Bakker, H.C.; Wiedmann, M.; Swaminathan, B.; Saunders. B.D. Listeria marthii sp. nov., isolated from the natural environment, Finger Lakes National Forest. International Journal of Systematic and Evolutionary Microbiology, 60(6): 1280- 1288, 2010.

Guillet, C.; Join-Lambert, O.; Le Monnier, A.; Leclercq, A.; Mechaï, F.; Mamzer-Bruneel, M. F.; Bielecka, M. K.; Scortti, M.a; Disson, O.; Berche, P.; Vazquez-Boland, J.; Lortholary, O.; Lecuit, M. Human listeriosis caused by Listeria ivanovii. Emerging Infectious Diseases, 16(1): 136-138, 2010.

Jay, J.M. Microbiologia de alimentos. $6^{a}$ ed., Porto Alegre: Artmed, 2005. p. 517-542.

Leclercq, A.; Clermont, D.; Bizet, C.; Grimont, P.A.; Le Flèche-Matéos, A.; Roche, S.M.; Buchrieser, C.; Cadetdaniel, V.; Le Monnier, A.; Lecuit, M.; Allerberger, F. Listeria rocourtiae sp. nov. International Journal of Systematic and Evolutionary Microbiology, 60(9): 2210-2214, 2010.

Liu, D. Identification, subtyping and virulence determination of Listeria monocytogenes, an important foodborne pathogen. Journal of Medical Microbiology, 55: 645-659, 2006. 
Mahgoub, S.A.; El-Mekkawy, R.M.; Abd ElHack, M.E.; El-Ghareeb, W.R.; Suliman, G.M.; Alowaimer, A.N.; Swelum, A. A. Inactivation of Listeria monocytogenes in ready-to-eat smoked turkey meat by combination with packaging atmosphere, oregano essential oil and cold temperature. AMB Express, 9(54): 1-9, 2019.

Maury, M.M.; Bracq-Dieye, H.; Huang, L.; Vales, G.; Lavina, M.; Thouvenot, P.; Disson, O.; Leclercq, A.; Brisse, S.; Lecuit, M. Hypervirulent Listeria monocytogenes clones' adaption to mammalian gut accounts for their association with dairy products. Nature Communications, 10 (2488): 1-12, 2019.

Oliveira, M.M.M.; Brugnera, D.F.; Alves, E.; Piccoli, R.H. Biofilm formation by Listeria monocytogenes on stainless steel surface and biotransfer potential. Brazilian Journal of Microbiology, 41: 97-106, 2010.

Possas, A.; Posada-Izquierdo, G.D.; PérezRodríguez, F.; Valero, A.; García-Gimeno, R.M.; Duarte, M.C.T. Application of predictive models to assess the infuence of thyme essential oil on Salmonella Enteritidis behaviour during shelf life of ready-to-eat turkey products. International Journal of Food Microbiology, 240(2): 40-46, 2017.

Robert, L.B.; Leon, G.M.G.; Melinda, M.H.; Timothy, C.J.; Richard, C.W. A review of Listeria monocytogenes: An update on outbreaks, virulence, dose-response, ecology, and risk assessments. Food Control, 75: 1-13, 2017.

Sakate, R.I.; Aragon, L.C.; Raghiante, F.; Landgraf, M.; Franco, B.D.G.M.; Destro, M.T. Quantificação de Listeria monocytogenes em salames fatiados embalados a vácuo. Archivos Latinoamericanos de Nutrición, 53(2): 184187, 2003.

Sampaio, I.B.M. Estatística aplicada à experimentação animal. Belo Horizonte: Fundação de Ensino e Pesquisa em Medicina Veterinária e Zootecnia, 1998. 221p.

Stinghen, A.E.M.; Albini C.A.; Souza, H.A.P.H.M. Coloração de Gram: como fazer, interpretar e padronizar. Curitiba: Microscience, 2002. $70 \mathrm{p}$. 